\title{
Near-Earth space plasma modelling and forecasting
}

\author{
Hal J. Strangeways $\left({ }^{1}\right)$, Ivan Kutiev $\left({ }^{2}\right)$, Ljiljana R. Cander $\left({ }^{3}\right)$, Stamatis Kouris $\left({ }^{4}\right)$, \\ Vadim Gherm $\left({ }^{5}\right)$, Diego Marin $\left({ }^{6}\right)$, Benito De La Morena $\left({ }^{7}\right)$, S. Eleri Pryse $\left({ }^{8}\right)$, Loredana Perrone $\left({ }^{9}\right)$, \\ Marco Pietrella $\left({ }^{9}\right)$, Stanimir Stankov $\left({ }^{10}\right)$, Lukasz Tomasik $\left({ }^{11}\right)$, Ersin Tulunay $\left({ }^{12}\right)$, \\ Yurdanur Tulunay $\left({ }^{12}\right)$, Nikolay Zernov $\left({ }^{5}\right)$ and Bruno Zolesi $\left({ }^{9}\right)$ \\ ( $\left.{ }^{1}\right)$ School of Electronic and Electrical Engineering, University of Leeds, Leeds, UK \\ $\left(^{2}\right)$ Geophysical Institute, Bulgarian Academy of Sciences (BAS), Sofia, Bulgaria \\ $\left(^{3}\right)$ Rutherford Appleton Laboratory, Didcot, UK \\ $\left({ }^{4}\right)$ Electrical and Computer Engineering Department, Aristotle University of Thessaloniki, Greece \\ $\left(^{5}\right)$ Department of Radiophisics, University of St. Petersburg, Russian Federation \\ $\left({ }^{6}\right)$ University of Huelva, Huelva, Spain \\ $\left(^{7}\right)$ Atmospheric Sounding Station El Arenosillo, INTA, Huelva, Spain \\ $\left({ }^{8}\right)$ Aberystwyth University, Aberystwyth, $U K$ \\ $\left({ }^{9}\right)$ Istituto Nazionale di Geofisica e Vulcanologia, Roma, Italy \\ $\left({ }^{10}\right)$ Royal Meteorological Institute, Brussels, Belgium \\ $\left.{ }^{(11}\right)$ Center for Space Research, Warsaw, Poland \\ ${ }^{(2)}$ Middle East Technical University (METU), Ankara, Turkey
}

\begin{abstract}
In the frame of the European COST 296 project (Mitigation of Ionospheric Effects on Radio Systems, MIERS) in the Working Package 1.3, new ionospheric models, prediction and forecasting methods and programs as well as ionospheric imaging techniques have been developed. They include (i) topside ionosphere and meso-scale irregularity models, (ii) improved forecasting methods for real time forecasting and for prediction of foF 2 , $M(3000) F 2$, MUF and TECs, including the use of new techniques such as Neurofuzzy, Nearest Neighbour, Cascade Modelling and Genetic Programming and (iii) improved dynamic high latitude ionosphere models through tomographic imaging and model validation. The success of the prediction algorithms and their improvement over existing methods has been demonstrated by comparing predictions with later real data. The collaboration between different European partners (including interchange of data) has played a significant part in the development and validation of these new prediction and forecasting methods, programs and algorithms which can be applied to a variety of practical applications leading to improved mitigation of ionosphereic and space weather effects.
\end{abstract}

Key words Ionospheric modeling - ionospheric forecasting - ionospheric predictions

\section{Introduction}

Ionospheric predictions of four different types are essential for mitigation of ionospheric

Mailing address: Dr. Hal J. Strangeways, University of Leeds, Leeds, UK; e-mail: H.J.Strangeways@leeds.ac.uk effects on radio systems: (i) Long-term ionospheric predictions that supply information on the ionosphere for a particular epoch of solar activity and can be used for planning radio systems operations. Their success depends on the long-term solar activity prediction (Belehaki et $a l ., 2007)$. (ii) Ionospheric now-casting where real- time observations are used to show the geographical and temporal variations of the ionospheric parameters (Zolesi et al., 2008). This type of ionospheric specification is important for management of radio services in near real-ti- 
me. (iii) Shortterm ionospheric prediction that can be based on extrapolation of past data sets, forecasting of a short-term disturbance index on which the ionosphere critically depends and monitoring of ionospheric propagation conditions in connection with solar-terrestrial parameters (Bremer et al., 2006). This is required to improve the quality and reliability of radiocommunication services, including frequency adaptive applications at MF and $\mathrm{HF}$ and transionospheric radio determination (Wheadon et al., 2006). (iv) Prediction of special disturbing factors like scintillations, which disturb GPS signals.

The terms of reference of Working Package 1.3 (WP 1.3) «Near-Earth space plasma modelling and forecasting» comprised a large area of near-Earth plasma modelling, supporting basic research, forecasting and radio communications. The structure of this paper follows the main topics of investigations in WP 1.3, viz: 2 . Topside model development and testing. 3. Development of techniques for real-time forecasting. 4. Forecasting of $f o F 2, M(3000) F 2$, MUF and TEC. 5. Tomographic imaging and model validation. 6. Modelling mid-scale (meso-scale) inhomogeneities at low-latitude (bubbles) and high-latitude (patches, blobs) to predict their scintillation effects.

A catalogue of ionospheric forecasting and predicting models developed in the framework of COST actions 238, 251, 271 and 296 has been compiled. The catalogue and brief description of all 18 models are available at: http://www.cost296.rl.ac.uk/word/CatalogueText.doc

\section{Topside models development and testing}

\subsection{Topside electron density model}

Triskova et al. (2007), have developed a model, providing electron density distribution at fixed altitudes as functions of invariant latitude and magnetic local time. A system of associated Legendre polynomials up to the 6th-order are fitted to the data from four satellites: Hinotori, ISS B, ISIS 1 , and ISIS 2 . The full model consists of submodels for individual seasons and altitude ranges. Triskova et al., 2007 have developed a topside electron density model by using vary-Chap functions for the scale height. At each given location, Ne submodels provide the anchor points for each altitude level, which are then used to construct the vertical profiles. This new topside presentation avoids the «kinks» in the profiles resulting from applying the Booker formulism. An example of the topside model is shown in fig. 1. It is one of options in the International Reference Ionosphere (IRI).

\subsection{TSMP-assisted topside reconstruction}

To improve the accuracy of the real time topside electron density profiles given by the Digisonde software, a new model-assisted technique is used (Kutiev et al., 2009). This technique uses the Topside Sounder Model (TSM), which provides the plasma scale height $(H s), \mathrm{O}^{+}-\mathrm{H}^{+}$ transition height $\left(H_{T}\right)$, and their ratio $R t=H s / H_{T}$, derived from topside sounder data of Alouette and ISIS satellites. Kutiev and Marinov (2007) introduced the concept of a new profiler «TSMP», using their scale height $(H s)$ and transition height $\left(H_{T}\right)$ models. TSMP provides the shape of the topside $\mathrm{N}(\mathrm{h})$ profile as the sum of the $\mathrm{O}^{+}$and $\mathrm{H}^{+}$profiles from $h m F 2$ up to GPS heights. The $\mathrm{O}^{+}$profile takes $\mathrm{Hs}$ as its own scale height $\left(H_{O}+=H s\right)$, at the transition height both densities are equal, and the scale height above $\mathrm{H}^{+}\left(\mathrm{H}_{H^{+}}\right)$is taken as 16 times the $\mathrm{O}^{+}$scale height. For the present analysis we use TSMP in the form:

$$
\begin{aligned}
& N_{0^{+}}=N_{m} \exp \left\{\frac{1}{2}\left[1-\frac{h-h_{m}}{H_{0^{+}}}-\exp \left(-\frac{h-h_{m}}{H_{0^{+}}}\right)\right]\right\}=F 2(h), \\
& N_{H^{+}}=N_{H^{+} m} \exp \left(-\frac{h-h_{T}}{H_{H^{+}}}\right) \\
& N e=F 2(h)+F 2\left(h_{T}\right) \exp \left(-\frac{h-h_{T}}{H_{H^{+}}}\right)
\end{aligned}
$$

$F 2\left(h_{T}\right)=N_{\mathrm{O}+}=N_{\mathrm{H}+}$ at transition height $\mathrm{h}_{\mathrm{T}}$. To calculate the topside density profile, TSMP needs values of $N m F 2$ and $h m F 2$ at the lower boundary (denoted as $\mathrm{Nm}$ and $\mathrm{hm}$ ), which are supplied by Digisonde measurements. In addition, the Digisonde also provides the topside scale 

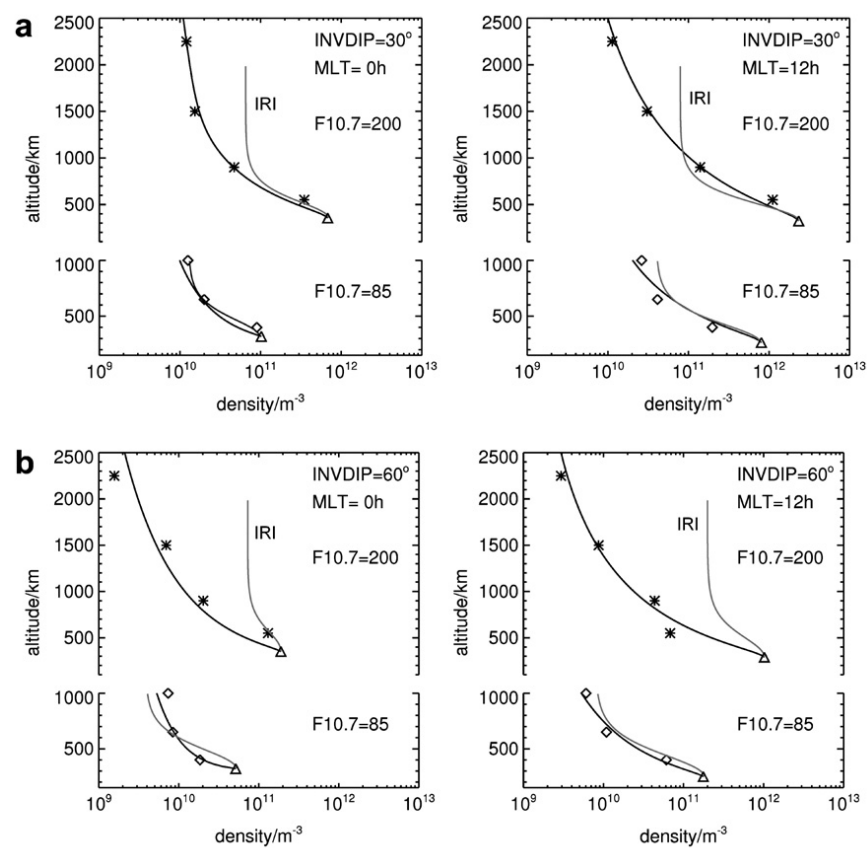

Fig. 1. Examples of Ne vertical profiles constructed by using densities at the sub-model altitudes, taken as anchor values, along with corresponding IRI models, for two levels of solar activity.

height $H d$. It is assumed that, for a particular moment in time, $H d$ represents the real conditions, and is therefore a better value than the average model value of $H s$. When $H d$ is specified, the corresponding transition height $\mathrm{h}_{\mathrm{T}}$ is obtained through the ratio $R t$, e.g. $h_{T}=H d$. Rt . To illustrate the general concept, we apply TSMP to reconstruct the topside Ne profile in two particular cases. Figure 2 show two examples of profile reconstruction for Athens.

\subsection{TSM model development and testing}

The topside ionospheric scale height $(H \mathrm{~s})$ and the $\mathrm{O}^{+}-\mathrm{H}^{+}$transition height $\left(H_{T}\right)$ are key ionospheric parameters which are of special interest when studying and modelling the plasma composition and dynamics. Recently, the $\mathrm{Hs}$ (Kutiev et al., 2006) and $H_{T}$ (Marinov et al., 2004) empirical models have been combined in a unified Topside Sounder Model (Kutiev and
Marinov, 2007). The database for these models has been built upon $170,000 \mathrm{Hs}$ and $H_{T}$ values deduced from electron profiles obtained via topside sounding measurements. For validation purposes, Stankov et al. (2007) compared TSM model results with those from the well-known models NeQuick and the Parameterized Ionospheric Model (PIM). Electron density profiles, in the altitude range $200-2000 \mathrm{~km}$, are obtained from the NeQuick and PIM models for a grid of input parameters, such as month, local time, geomagnetic latitude, and solar activity. The scale height and transition height were extracted from the model profiles in the same way they were extracted from the measured topside sounder profiles. Their values are then compared with the respective values provided by the TSM model. Comparison of the scale height and the transition height show that, in general, the NeQuick and PIM models provide higher values of both scale height and transition height than those of TSM. 

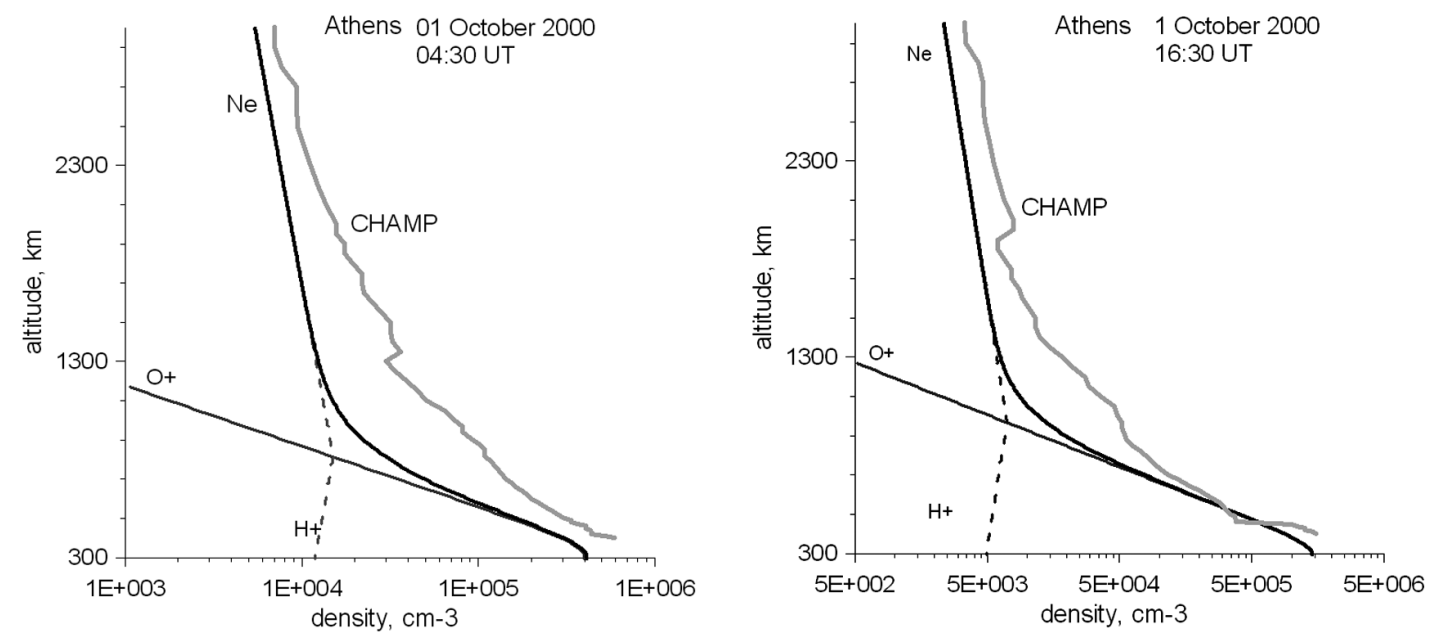

Fig. 2. TMSP profile reconstruction for Athens: at 04:30 UT (left) and 16:30 UT (right) on 1 October 2000. TSMP-assisted Digisonde (TaD) profiles are shown the heavy line; solid and dashed curves show $\mathrm{O}^{+}$and $\mathrm{H}^{+}$distributions respectively. For comparison, CHAMP-based reconstruction (Heise et al., 2002) profiles are given by the grey curves.

Briefly, the comparison results for the plasma scale height can be summarized as follows:

- PIM - generally highest values during high solar activity

- PIM - unusually high values during an HSA day at low and middle latitudes

- NeQuick - highest values (unusually high) in LSA winter.

The comparison results for the ion transition height can be summarized as follows:

- PIM - systematically higher (probably overestimated) values at HSA

- NeQuick - relatively weaker dependence on solar activity

- NeQuick - discontinuities over the equator occur at night time.

\subsection{Modeling TEC and slab thickness variations}

Considerable efforts have been devoted to quantifying the response of TEC to changes in solar activity, location, season and time of day. Kouris et al. $(2006$; 2008) found that TEC is highly correlated with solar activity and latitude and also with season. Applying a least squares analysis to the vertical TEC obtained from GPS measurements at different European locations and the corresponding solar flux density data at $10.7 \mathrm{~cm}$, the total electron content relative to the quiet sun level $\left(T_{\mathrm{o}}\right)$ at each hour/ month/ location is counted. Then, these $T_{\mathrm{o}}$ values are correlated with corresponding values of the seasonal parameter $\cos \chi$ at noon at each location according to the following least squares equation

$$
T_{\mathrm{o}}=k\left(\cos \chi_{12}\right)^{\mathrm{m}}
$$

where $\cos \chi_{12}$ is the cosine of the solar zenith angle at noon (a seasonal parameter). The calculated values of the factor ' $k$ ' and the exponent ' $m$ ' determined by using monthly median vertical TEC values measured at noon and/or any other hour, exhibit a latitudinal dependence (Kouris et al., 2009) since TEC depends on latitude.

The slab thickness, an important parameter in the determination of $N 2_{\max }$ from TEC measurements, is also investigated and some specifications are established. It has a diurnal variation (Kouris et al., 2006) in winter from about 200 $\mathrm{km}$ to $450 \mathrm{~km}$ on average, whereas in equinoxes 
and summer, this ranges from circa $300 \mathrm{~km}$ to $450 \mathrm{~km}$ depending on the time of day. In winter and equinoxes the nighttime values are much higher than the day-time, whereas in summer the opposite occurs so that the day values are higher than the nighttime ones. The predawn peak is found to occur in winter and equinoxes from about $500 \mathrm{~km}$ to $700 \mathrm{~km}$ and in summer from circa $400 \mathrm{~km}$ to $450 \mathrm{~km}$. The monthly average values of the slab thickness all over Europe are practically the same, within a range of circa 20 $\mathrm{km}$ to $30 \mathrm{~km}$ during day-time. Some greater differences exist during nighttime due to disturbed conditions which depend on location and occur predominantly during nighttime (Fotiadis et al., 2004; Kouris et al., 2005). The equivalent slab thickness is independent of solar activity and latitude (Kouris et al., 2008) but depends strongly on season (Kouris et al., 2009).

A mean value of the equivalent slab thickness for day-time conditions (cosine of the solar zenith angle greater or equal to 0.10 ) can be determined from the following analytical expression:

$$
\text { Est. }=370\left(\cos \chi_{12}\right)^{0.44}
$$

For nighttime conditions (i.e. cosine of the solar zenith angle less than 0.10 ) a mean value can be calculated from the equation:

$$
\text { Est }=313\left(\cos \chi_{12}\right)^{-0.24}
$$

These relationships are valid for locations within the latitudinal range of 30 to circa 60 degrees. Higher latitude locations are excluded because of the decreased stability of the $F$-region in this zone (Rawer et al., 2003). Neglecting diurnal and seasonal variations, an overall mean slab thickness for Europe (circa $30^{\circ} \mathrm{N}$ to $55^{\circ} \mathrm{N}$ ) can be taken as $323 \mathrm{~km}$ with a standard deviation less than $50 \mathrm{~km}$.

\section{Development of techniques for real-time forecasting}

A study has been carried out on those major areas where our current physical understanding and recent advances can lead to positi- ve prediction, forecasting and mitigation of the expected effects of ionospheric activity on the near Earth space environment and on technological systems which operate within this environment (Cander and Mihajlovic, 2005; Cop et al., 2008; Cander and Ciraolo, 2008).

The results show some of the key links between solar activity and the various physical processes, which govern ionospheric plasma structure. Specific examples during extremely intense solar event as well as during low solar activity illustrate how ionospheric monitoring techniques that have contributed immense data sets and related empirical and theoretical formulations can be incorporated in different models for real-time operational applications (Jansen et al., 2006; Cander 2009).

An example of the long-running services developed in the course of the European ionospheric COST actions is the «Space Weather Web Facilities for Radio Communications Users» at Rutherford Appleton Laboratory, UK since 1998. In this on-line service the real-time ionospheric observations have been integrated into suitable methods and models to provide a number of products. An overall extensive validation procedure for these products has shown that the combined subsequent ionospheric predictions are essential for any mitigation of ionospheric effects on radio systems: 1) Long-term ionospheric predictions that supply information on the ionosphere for a particular epoch of solar activity and can be used for planning radio systems operations. Their success depends on the long-term solar activity prediction (Belehaki et al., 2007); 2) Ionospheric now-casting where real-time observations are used to show the geographical and temporal variations of the ionospheric parameters (Zolesi et al., 2008). This type of ionospheric specification is important for management of radio services in near real-time; and 3) Shortterm ionospheric forecasting (STIF) that can be based on extrapolation of past data sets, forecasting of a short-term disturbance index on which the ionosphere critically depends and monitoring of ionospheric propagation conditions in connection with solar-terrestrial parameters (Muhtarov et al., 2002; Bremer et al., 2006).

Figure 3 shows a comparison between the 
foF 2 produced by the short-term ionospheric forecasting method and the data from Chilton $\left(51.5^{0} \mathrm{~N},-1.3^{0} \mathrm{E}\right)$ ionosonde. It can be seen that this forecasting facility performs very well during quiet geomagnetic periods. Although it falters at intense geomagnetic events, it still provides a valuable ionospheric predictor over Europe, having in mind the storm distribution given in fig. 4 .

\section{Forecasting of FoF2, M(3000)F2, MUF and TEC}

\section{1. foF2 forecast during severe geomagnetic activity in Rome observatory}

To forecast the ionospheric response to geomagnetic storms, geomagnetic indices have been introduced taking into account their history (Wrenn, 1987; Wu and Wilkinson, 1995; Perrone and De Franceschi, 1999). One of these is ap $(\tau)$ (Wrenn, 1987) derived with a time weighted series accumulation from the geomagnetic planetary index ap. The attenuation multiplier $\tau$ ranges between 0 and 1 and determines the weights assigned to past ap values. The larger is $\tau$, the smoother are the ap variations. An improved linear correlation was found between transformed data obtained from hourly and monthly median values of $f o F 2$ and $\operatorname{ap}(\tau)$ with $\tau=0.8$ (Perrone and De Franceschi, 1999). The transformed data of $f o F 2$ that gives the best result is $\log (N m F 2(t) / N m F 2 M(t))$, where $N m F 2(t)$ is the hourly value of the maximum electron density at the $F 2$ peak and the suffix $M$ indicates the monthly median value ( $\mathrm{Wu}$ and Wilkinson, 1995). Instead for the monthly median representing the «quiet» ionosphere, an average is calculated by Perrone et al. (2007). It is obtained considering, for a selected hour, foF 2 values with $\operatorname{ap}(\tau) \leq 7$ in the thirty days preceding the day for which we want to have the «quiet» value. This average is called the «daily» mean.

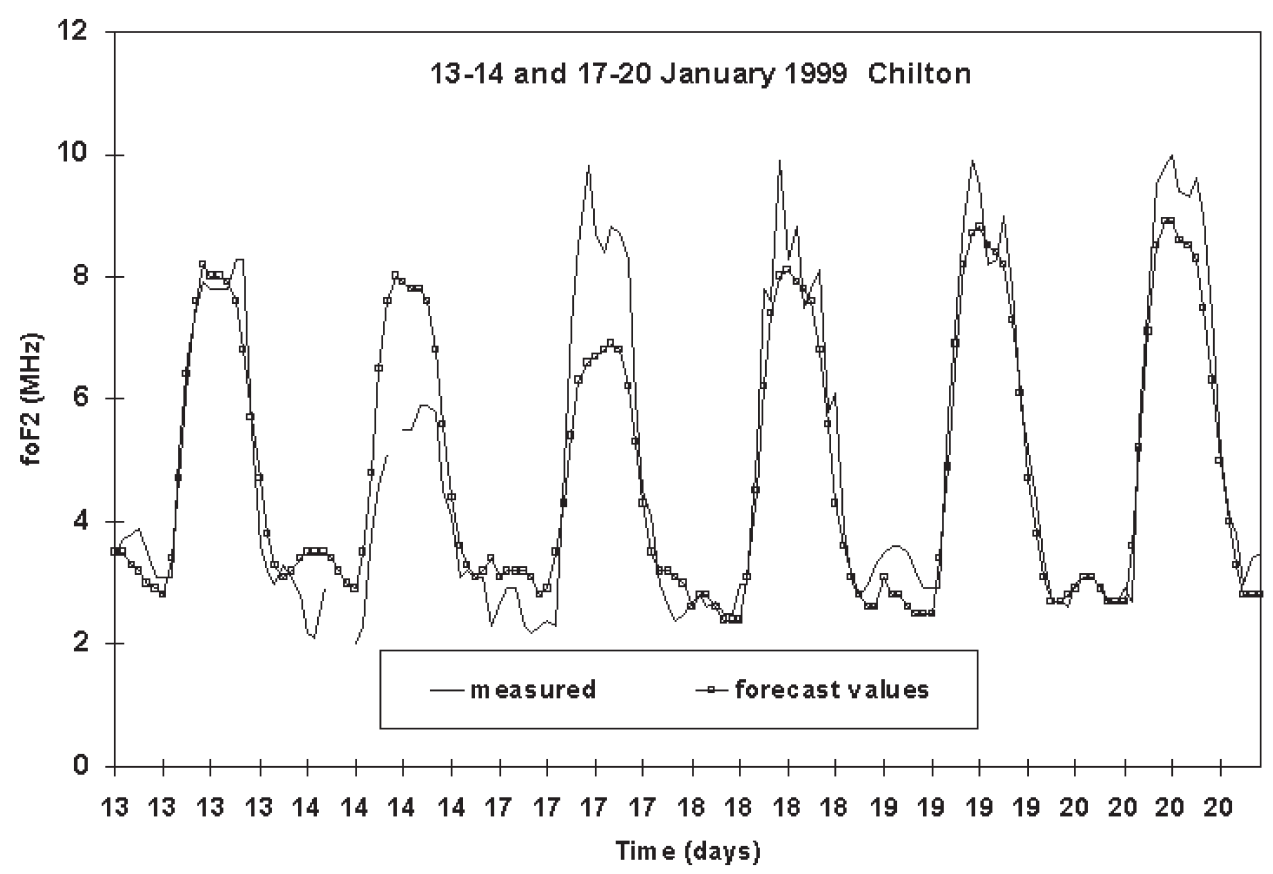

Fig. 3. Measured and 24 hours in advance forecast $f \circ F 2$ values during quiet and disturbed days in January 1999 at Chilton ionospheric station. 
The data utilized are the foF 2 hourly values measured at the Rome $\left(41.9^{\circ} \mathrm{N} ; 12.5^{\circ} \mathrm{E}\right)$ observatory. Geomagnetic storms with a maximum of ap $\leq 132$ are classified as strong events.

An example of $f_{o F}$, forecast with the relationship between the foF 2 transformed data and $\operatorname{ap}(\tau)$, is presented in fig. 5, which illustrate the results of forecasting for the period 12-17 July 2000 , when a negative ionospheric storm occurred. The r.m.s. of forecast is $1.23 \mathrm{MHz}$ and for the «daily mean» it is $2.0 \mathrm{MHz}$.

The model was further developed to adapt it for different seasons and ap levels. The new model, called IFELMOR (Ionospheric Forecasting Empirical Local Model Over Rome, Pietrella and Peronne, 2008) uses different sets of coefficients for each month of the year and several ranges of $\operatorname{ap}(\tau)$. IFELMOR predictions are compared in table I with those of the IRI-STORM model in terms of r.m.s. error for selected days with very disturbed ionospheric conditions (daily mean of $a p(t=0.9), a p(\tau=0.9)>70)$. The best performance is labelled in bold.

\subsection{Neurofuzzy techniques applied to model and predict the F2-layer critical frequency foF 2}

A new methodology to predict the ionospheric F2-layer critical frequency, $f_{o} F 2,1-24$ hours in advance has been advanced. The proposed method is based on artificial intelligence techniques, specifically, on neuro-fuzzy modelling, very little used in ionospheric modelling until now. Such techniques have a natural capability to model well non-linear and complex systems. Neurofuzzy models incorporate from fuzzy models the ability to understand and connection with physical processes and, on the other hand, from neural networks based models, the capability of adaptation and learning. Neurofuzzy models allow incorporation of ex-

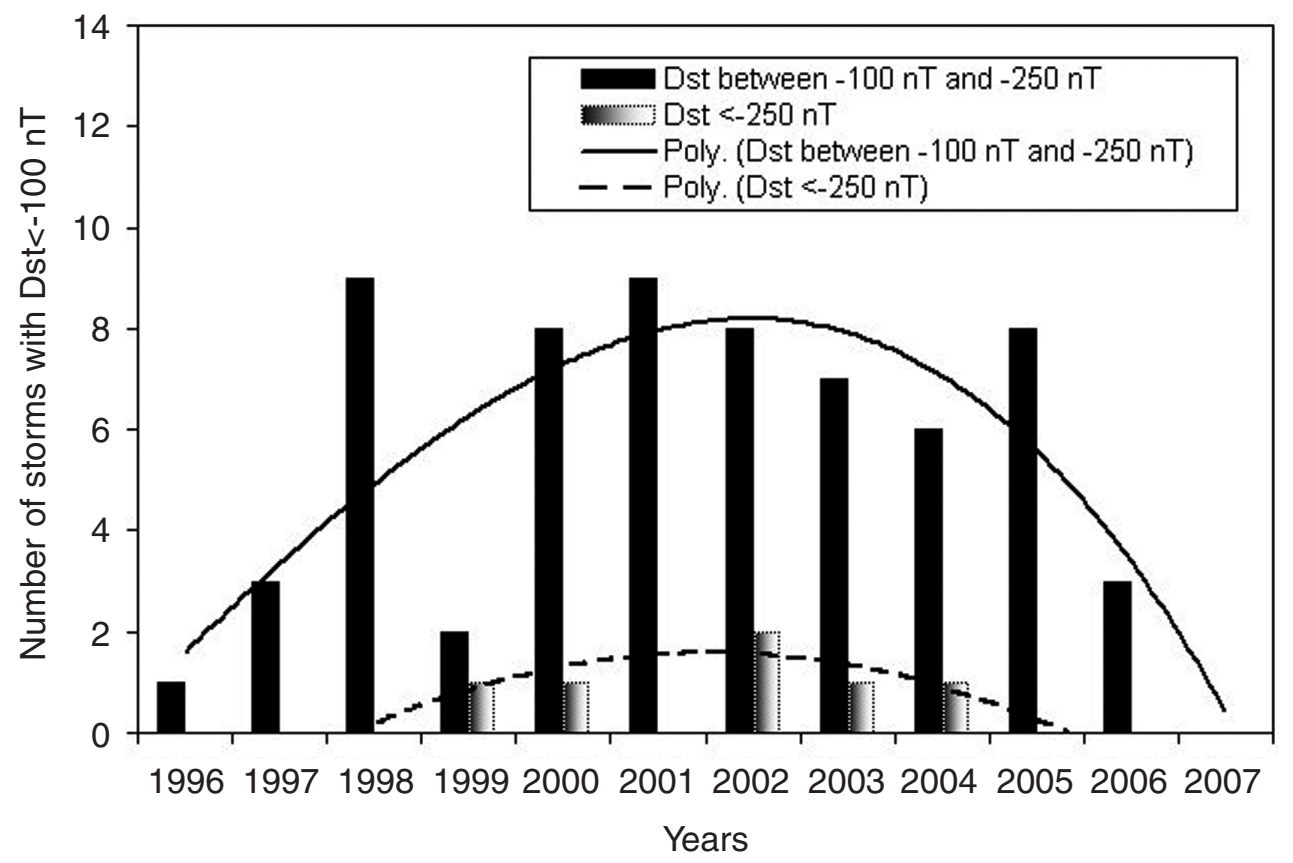

Fig. 4. Years count of magnetic storms during solar cycle 23 (1996-2007). 
Table I. Comparison of predictions between IFELMOR and IRI-STORM.

\begin{tabular}{|c|c|c|c|c|c|c|}
\hline Day/month/year & $\begin{array}{l}\text { IFELMOR } \\
\text { r.m.s (MHz) }\end{array}$ & $\begin{array}{l}\text { STORM MEDIANS } \\
\text { r.m.s }(\mathrm{MHz})\end{array}$ & $\begin{array}{l}\text { MEDIANS } \\
\text { r.m.s (MHz) }\end{array}$ & $\begin{array}{l}\mathrm{STORM}_{f o F 2 Q T} \\
\text { r.m.s }(\mathrm{MHz})\end{array}$ & $\begin{array}{c}f o F 2 \mathrm{QT} \\
\text { r.m.s (MHz) }\end{array}$ & $\mathrm{ap}(\mathrm{t}=0.9)$ \\
\hline 16th July 2000 & 0.47 & 0.56 & 1.90 & 0.42 & 2.24 & 77.8 \\
\hline 31th March 2001 & 1.70 & 2.81 & 2.97 & 4.11 & 4.48 & 77.1 \\
\hline 1th April 2001 & 1.54 & 1.71 & 1.98 & 2.02 & 3.34 & 78.7 \\
\hline 30th October 2003 & 0.87 & 1.87 & 1.89 & 6.78 & 6.83 & 125.1 \\
\hline 31th October 2003 & 0.83 & 2.33 & 2.34 & 6.62 & 6.65 & 147.8 \\
\hline 1th November 2003 & 1.88 & 0.83 & 0.73 & 3.03 & 2.83 & 81.6 \\
\hline 21th November 2003 & 0.73 & 0.76 & 0.80 & 1.55 & 1.40 & 77.8 \\
\hline Global r.m.s. error & 1.34 & 1.78 & 1.94 & 4.02 & 4.25 & \\
\hline
\end{tabular}

Table II. Relative mean and standard deviations between observations and predictions.

\begin{tabular}{lccccccc}
\hline \hline \multicolumn{7}{c}{ Lead Time (hours) } \\
\hline RMD(SD) & 1 & 2 & 3 & 6 & 12 & 18 & 24 \\
& 3.92 & 7.91 & 8.24 & 9.11 & 9.73 & 9.88 & 9.92 \\
& $(1.65)$ & $(1.36)$ & $(1.45)$ & $(1.51)$ & $(1.83)$ & $(2.06)$ & $(1.85)$ \\
\hline
\end{tabular}

pert knowledge in different parts of the modelling process.

To predict $f o F 2 n$ hours ahead, the values of foF 2 at the current time $t$, at two previous hours, and 24 and 25 hours in the past are considered, along with the respective ap values. For predictions at 1 or 2 hours ahead, foF 2 values from the previous day are not taken into account.

In order to test the $f o F 2$ neurofuzzy models, the relative mean deviation (RMD) between observations and short-term $f_{o} F 2$ predictions (1-24 hour lead times) were calculated for 100 periods of 3 consecutive days. Values of foF 2 were observed at Slough in 1980-82. 62.1\% of the selected 300 days are geomagnetic quiet days $(\mathrm{Ap}=10)$, the other $37.9 \%$ correspond to moderate geomagnetic activity $(10<\mathrm{Ap}<40)$. As can be seen from table II, best predictions are made for 1-3 hours in advance, where the RMD varies from approximately 4 to $8 \%$. For larger lead times, the RMD stays approximately the same (around 9-10\%) and the prediction accuracy does not depend significantly on the lead time.

For lead times larger than 3 hours, prediction accuracy decreases significantly, with an RMD around 20-30\%. These conclusions were reached by calculating the RMD over 15 periods of 3 days with Ap $>40$. Despite this poor accuracy for lead times larger than 3 hours, the great efficiency of the neurofuzzy model to predict 1-3 hours in advance, even under very disturbed periods, should be noted. To illustrate this result, the variations of observed and 1hour predicted $f_{o F} 2$ values for three time periods, when effects of strong negative storms were observed, are represented in fig. 6. It can be noticed how both observed and predicted $f o F 2$ variations are very close. 


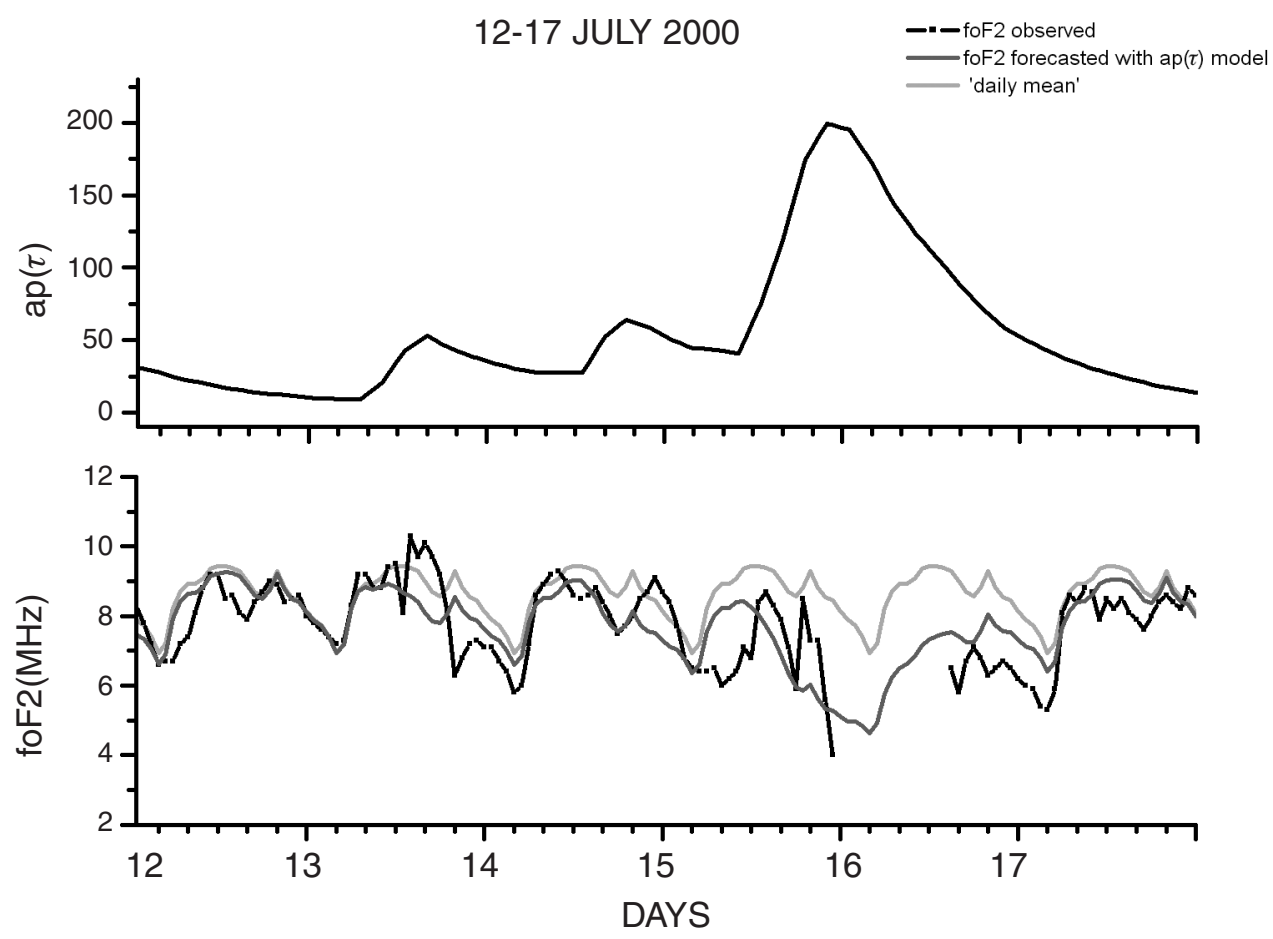

Fig. 5. The behaviour of $f o F 2$ observed, forecasted and of the «daily» mean for 12-17 July 2000.

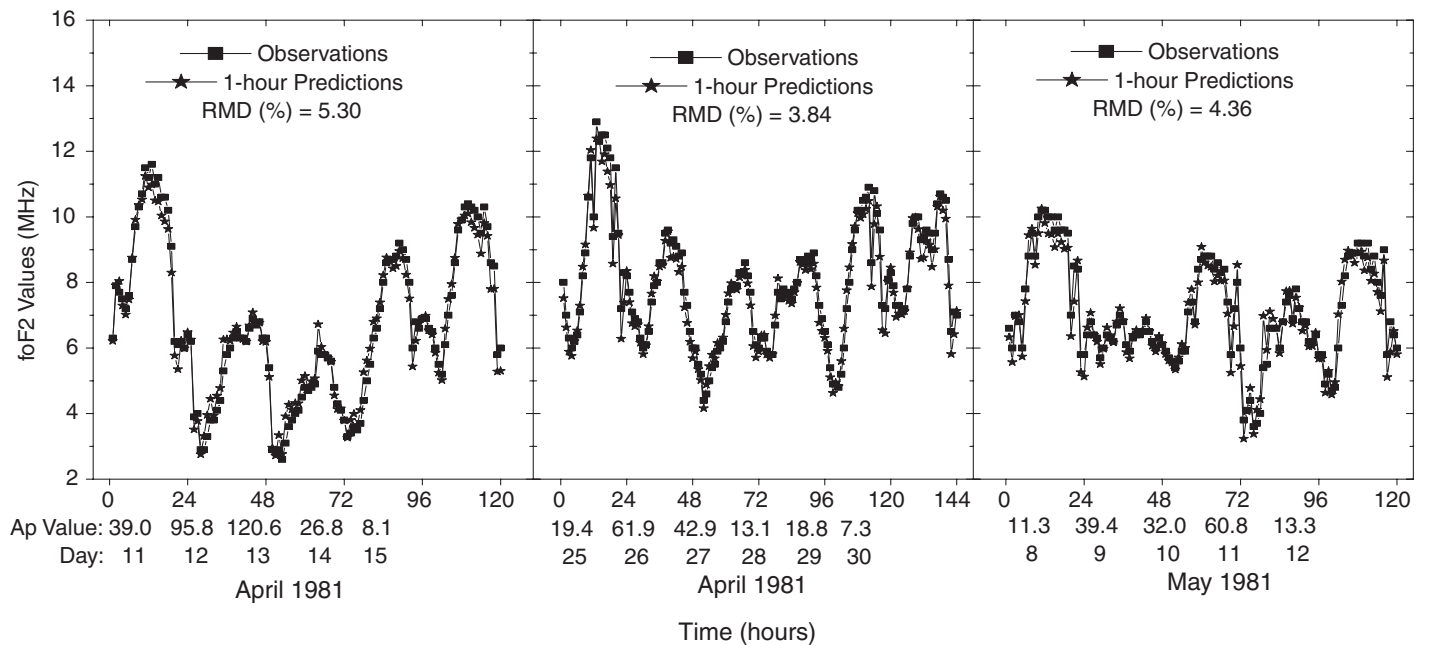

Fig. 6. 1-hour prediction examples over 3 very disturbed periods. The Ap index value is given to indicate the geomagnetic activity level. 
Table III. RMS error for prediction 24 hours ahead.

\begin{tabular}{ccc}
\hline Name & RMS foF2 $[\mathrm{MHz}]$ & RMS M3000f2 \\
\hline El Arenosillo & 1.15 & 0.2 \\
Juliusruh & 0.90 & $\mathrm{x}$ \\
Loparskaya & 1,2 & 0.17 \\
Sofia & 0.90 & $\mathrm{x}$ \\
Tashkent & 1,70 & 0.17 \\
Tortosa & 0.98 & 0.17 \\
\hline
\end{tabular}

\subsection{Forecasting of foF 2 and $\mathrm{M}(3000) \mathrm{f} 2$ using the Nearest Neighbour (NN) algorithm}

Forecasting of ionospheric characteristics has been accomplished by means of the nearest neighbour and modified neural network algorithms. Algorithms were used for data gaps correction, as well as the characteristics' forecast. They are determined for the European area. Both models are in operational use at RWC Warsaw (Space Research Centre). A full description is given on the COST 296 WG1 home page (http://rwc.cbk.waw.pl/cost296/wg1/) (Ionosphere forecasting models). Table III illustrates the quality of forecast through the RMS error for prediction 24 hours ahead.

\subsection{Neural Network based Forecasting, Maps, and Process Identification}

The Middle East Technical University (ME$\mathrm{TU}$ ) data driven models have proven to be powerfull in forecasting the parameters of the non-linear processes including the ionospheric processes. These models consist of Neural Networks (NN), Neuro Fuzzy Networks (NFN), Genetic Programming (GP) and Cascade Models.

The models are capable of performing nowcasting and forecasting of ionospheric parameters such as ionospheric critical frequancy ( $f o F 2$ ), Total Electron Content (TEC) values up to 24 hours in advance for single and multistations and also performing forecast mapping over the COST 296 area during disturbed Space Weather (SW) conditions (Tulunay et al., 2004; Tulunay et al., 2006; Senalp et al., 2008).

Some illustrative examples for mapping application are presented. In the first example, the METUNN-C model has been employed to forecast the GPS TEC grid values over Europe (Senalp, 2007). Bezier surfaces are used for mapping including the SW events in November 2003 whose TEC Absolute Error Map is presented in fig. 7.

In the second example, as illustrated in fig. 8 , the forecast $f_{o F} \mathrm{~F}$ values are obtained by using the METU Fuzzy-Neural Network model (METU-FNN) (Altuntas, 2007) during the Halloween 2003 storm and the mapping is performed using Genetic Programming (GETY) (Yapici, 2007).

\subsection{Tests of MUF forecasts}

In order to test the preliminary results obtained in a previous research (Zolesi et al., 2008), the hourly MUF measurements were compared with the hourly MUF predicted by the longterm models ASAPS, ICEPAC and SIRM\&LKW and with the hourly values of MUF predicted by the nowcasting models SIRMUP\&LKW and ISWIRM\&LKW. The comparisons in terms of the global r.m.s. error between the long term models and the nowcasting models, carried out for the 33 days selected among different seasons and geomagnetic conditions, quantified in table IV how much better is the nowcasting pre- 


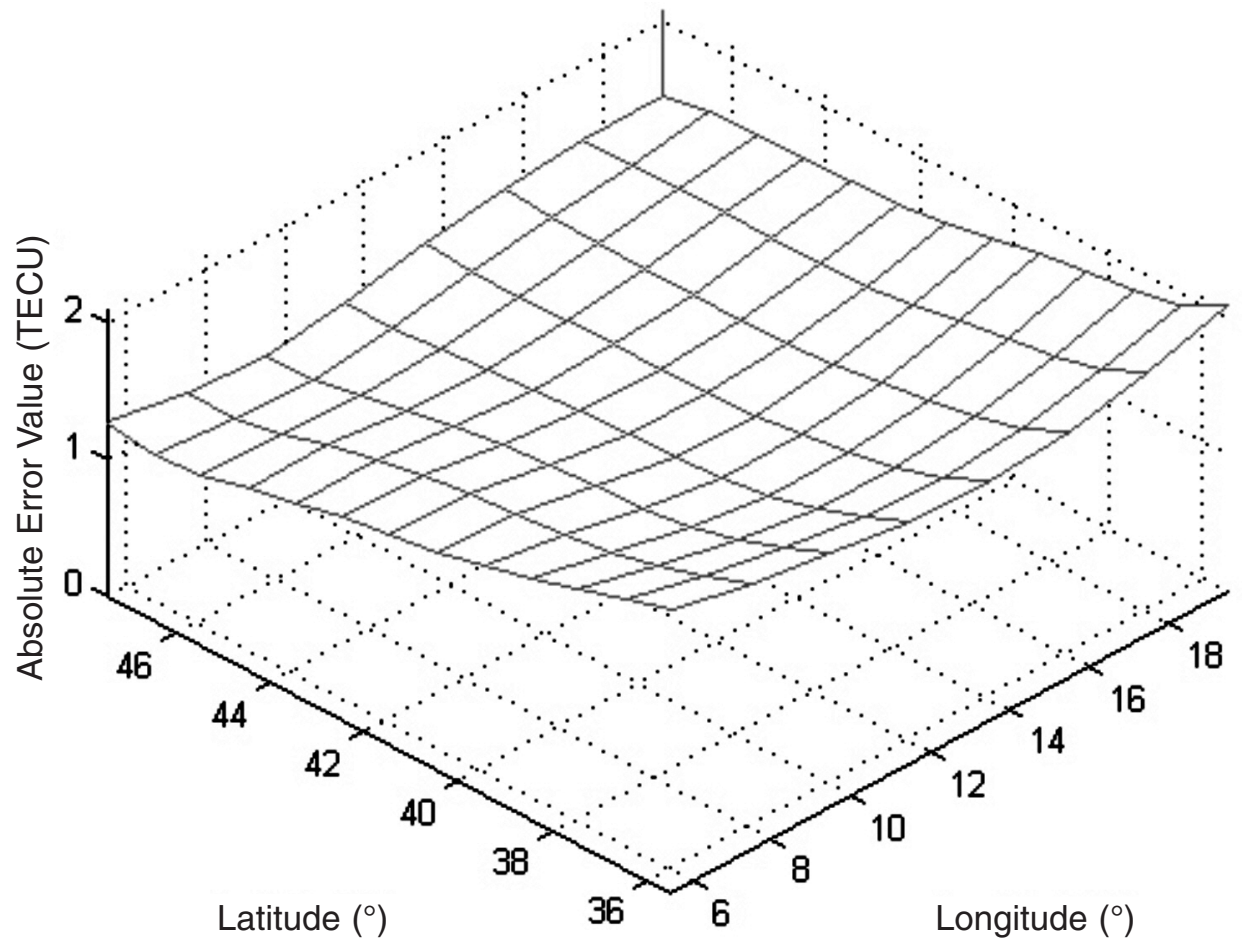

Fig. 7. Absolute error map for observed and $1 \mathrm{~h}$ ahead forecast TEC during 16-29 Nov. 2003.

diction of individual days than the longterm model prediction during winter months and equinoctial months, as well as under moderate, disturbed, and very disturbed geomagnetic conditions (Pietrella et al., 2009).

\section{Tomographic imaging and model validation}

During the evening and nighttime the midlatitude ionosphere is separated from the auroral region by the main ionisation trough (Pryse et al., 2006a). The mechanisms that form and sustain the trough have been studied for many years but are still open to debate, in particular in the post magnetic midnight sector. Recent studies by the Solar System Physics research group at Aberystwyth University have shown the role of plasma drawn across the polar region in sustaining the poleward wall of the trough (Pryse et al., 2007). Radiotomography observations by the International Ionospheric Tomography Community (IITC) have been the focus of the work, reinforced by measurements from other experimental techniques and the Coupled Thermosphere-Ionosphere-Plasmasphere (CTIP) model. In turn, the observations have served to validate and develop the model.

Several studies have investigated the role that plasma transported from the polar region plays in the nightside ionosphere. One example using observations by radiotomography and the EISCAT and SuperDARN radars concluded that in this instance enhanced ionisation was drawn from the polar region, through the Harang discontinuity and into the pre-midnight sector where it was restructured into a boundary blob (Pryse et al. 2006b). Radiotomography observations in Scandinavia and UK (Middleton 


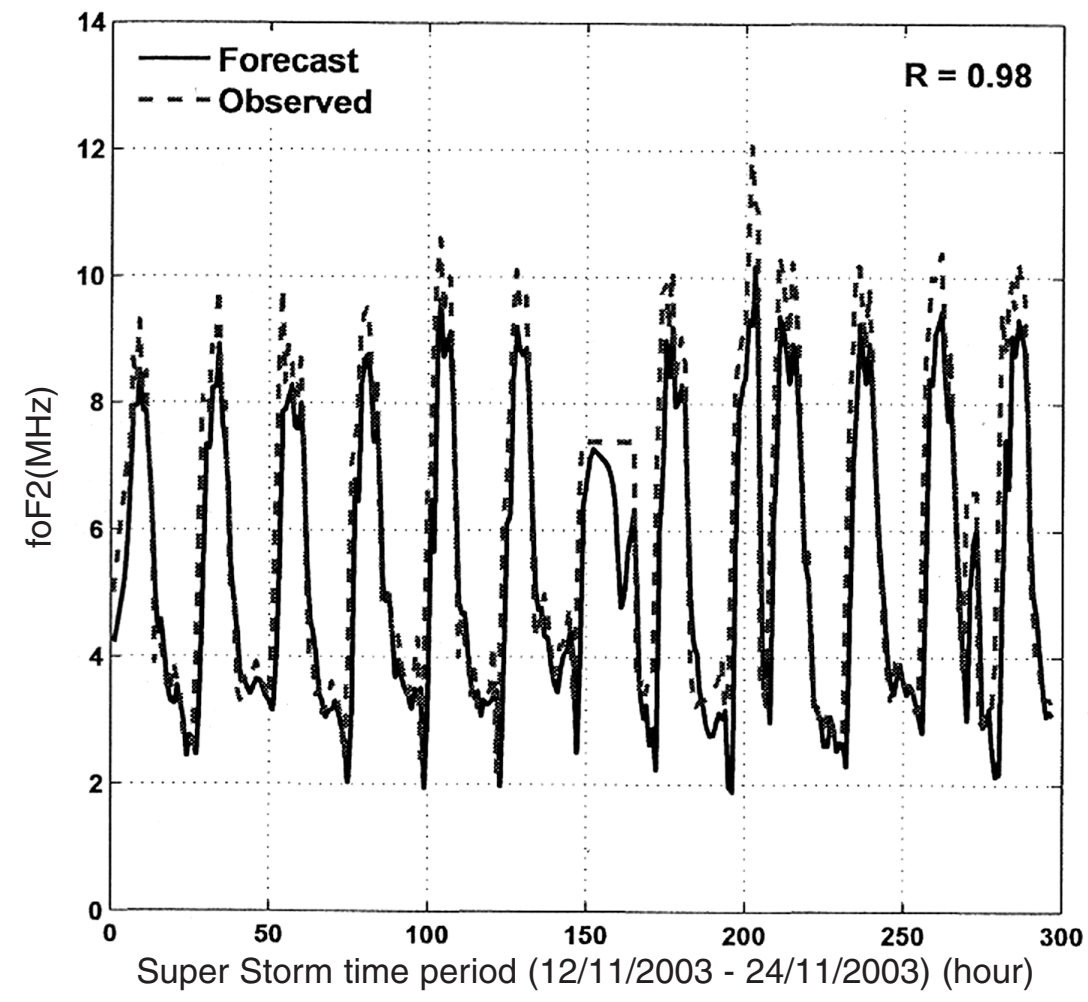

Fig. 8. Superimposed are the observed and 1-h in advance forecast values of foF 2 for Sofia between 12 and 24 Nov. 2003.

Table IV. Comparison of RMS errors between nowcasting and long term models.

\begin{tabular}{lcccccc}
\hline \hline & $\begin{array}{c}\text { ASAPS } \\
\text { r.m.s. (MHz) }\end{array}$ & $\begin{array}{c}\text { SIRM } \\
\text { r.m.s. (MHz) }\end{array}$ & $\begin{array}{c}\text { ICEPAC } \\
\text { Prof CCIR } \\
\text { r.m.s. (MHz) }\end{array}$ & $\begin{array}{c}\text { SIRMUP\&LKW } \\
\text { r.m.s. (MHz) }\end{array}$ & $\begin{array}{c}\text { ISWIRM\&LKW } \\
\text { r.m.s. (MHz) }\end{array}$ & ap daily mean \\
\hline 23 June 2005 & 3.21 & 2.89 & 3.36 & 2.29 & $\mathbf{1 . 6 1}$ & 50 \\
10 July 2005 & 3.26 & 2.59 & 3.33 & 2.18 & $\mathbf{1 . 5 2}$ & 57 \\
12 September 2005 & 2.51 & 2.70 & 2.50 & $\mathbf{1 . 5 5}$ & 2.32 & 75 \\
18 January 2005 & 3.48 & 4.06 & 2.79 & $\mathbf{2 . 5 2}$ & 3.11 & 84 \\
15 May 2005 & 3.30 & 2.80 & 3.18 & 1.82 & $\mathbf{0 . 9 7}$ & 87 \\
8 May 2005 & 3.77 & 3.28 & 3.70 & 2.05 & $\mathbf{0 . 9 8}$ & 91 \\
24 August 2005 & 3.83 & 3.22 & 3.99 & $\mathbf{2 . 4 2}$ & $\mathbf{2 . 6 5}$ & 102 \\
Global r.m.s. error & 3.13 & 3.35 & 3.26 & 2.12 & $\mathbf{2 . 0 3}$ & \\
\hline
\end{tabular}


et al., 2008) under IMF Bz negative revealed a prominent poleward trough wall in the post magnetic midnight sector. Using the CTIP model and multi-instrument measurements the ionisation of this wall was interpreted as arising from a tongue-of-ionisation (TOI) drawn antisunward through the polar cap, through the Harang discontinuity and into the dawn sector where it formed the trough wall.

Other studies have shown dayside ionisation drawn antisunward towards the nightside under conditions of IMF $\mathrm{Bz}$ positive. An example using radiotomography measurements from the Scandinavian and Greenland sectors (Middleton et al., 2005) revealed enhanced density on the periphery of the polar cap in the afternoon and evening. This was interpreted as a TOI being drawn around lobe cells in the polar cap, rather than being drawn directly across the polar region. Wood et al. (2008) investigated the spatial variation in the nighttime ionisation under $\mathrm{Bz}$ positive, and revealed enhanced ionisation on the nightside under $\mathrm{Bz}$ positive, but with a reduction in density in a region where it was likely that the lobe cells were blocking the transit of ionisation from the dayside to the nightside.

Initial comparisons of the CTIP model output with observations (Middleton et al., 2008) showed disparities in the detail of the location and density of the poleward trough wall. In a subsequent study, electric potential patterns shaped by SuperDARN plasma flow observations were used to replace library patterns as input to the model. A significant improvement was obtained between the observed and modelled enhancements forming this wall (Pryse et al., 2009; Whittick et al., 2009).

Sample comparisons between the model and observations are shown in fig. 9 under conditions of IMF Bz negative, where the density enhancement in the equatorward field-of-view of the panels represents a cross-section through a TOI swept into the post-magnetic midnight sector to form the poleward trough wall.

For conditions of IMF Bz positive, the CTIP model with a SuperDARN electric potential pattern yielded dayside ionisation drawn antisunward around the periphery of the polar region, in accord with tomography observations under IMF Bz positive (Pryse et al., 2009). The library of electric potential patterns, used with CTIP prior to the use of SuperDARN observations, did not include lobe cells characteristic of IMF $\mathrm{Bz}$ positive required to reproduce a spatial plasma distribution akin to that observed.

\section{Modelling mid-scale (meso-scale) inhomogeneities at low-latitude (bubbles) and hight-latitude (patches, blobs) for scintillation predictions}

An analytical model has been developed for mid-scale (meso-scale) ionospheric inhomogeneities in the background ionosphere occurring either as patches in the high-latitude ionosphere or bubbles in the low latitude/equatorial ionosphere.

The mid-scale irregularity model is embedded in the large-scale background ionosphere in order to investigate and predict their scintillation effects. Separate models were constructed for both ionospheric electron density bite-outs (bubbles) and enhancement (patches) together with the smaller rod-like irregularities contained within them. To construct the mid-scale inhomogeneity model, a basic function was employed of the form:

$$
\begin{aligned}
& F\left(x, x_{1}, a_{1}, x_{2}, a_{2}\right)=\left[1+\exp \left(-\frac{x-x_{1}}{a_{1}}\right)\right]^{-1}- \\
& -\left[1+\exp \left(-\frac{x-x_{2}}{a_{2}}\right)\right]^{-1}, x_{1}<x_{2} .
\end{aligned}
$$

The pattern given by function (6.1) is shown in fig. 10. The 3-dimensional structure can be modelled by means of functions of type (6.1) as the product:-

$$
\begin{aligned}
& \Phi\left(r, r_{1}, v_{1}, r_{2}, v_{2}\right)=F\left(x, x_{1}, a_{1}, x_{2}, a_{2}\right) \\
& F\left(y, y_{1}, b_{1}, y_{2}, b_{2}\right) \cdot F\left(z, z_{1}, c_{1}, z_{2}, c_{2}\right) \\
& r=\{x, y, z\}, r_{1}=\left\{x_{1}, y_{1}, z_{1}\right\}, r_{2}=\left\{x_{2}, y_{2}, z_{2}\right\} \\
& v_{1}=\left\{a_{1}, b_{1}, c_{1}\right\}, v_{2}=\left\{a_{2}, b_{2}, c_{2}\right\}
\end{aligned}
$$

In the approximation of the «frozen drift» the positions of the «walls» are functions of time whereas the shape of a structure is kept the same. 

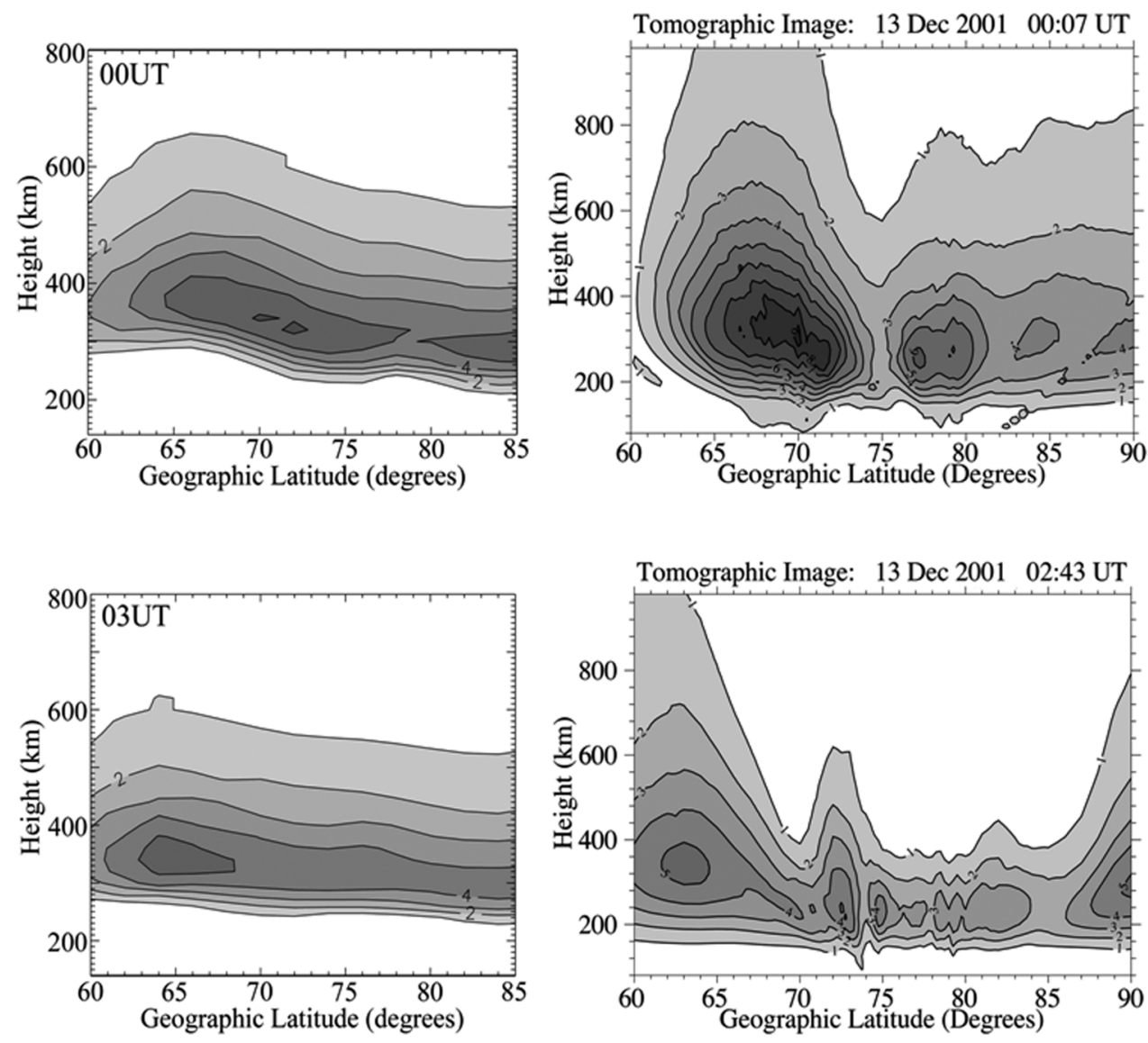

Fig. 9. Plasma distributions modelled by the CTIP model (left-hand-side panels) at the $18^{\circ} \mathrm{E}$ meridian in the northern hemisphere at 00UT and 03UT on 13 December 2001, and corresponding radio tomography observations (right-hand-side panels). The contours are in units of $10^{11} \mathrm{~m}^{-3}$.

Embedding the mid-scale inhomogeneity into the ionosphere is managed by modulation of the background ionosphere utilizing equation 6.2:

$$
N e(r, t)=N e_{0}(r) \cdot\left[1+A \cdot \Phi\left(r, r_{1}(t), v_{1}, r_{2}(t), v_{2}\right)\right]
$$

$A$ is a constant, which is positive for an enhanced level of the electron density in a local structure and negative for a depletion. To model the electron density fluctuations, a fully three-dimensional inverse power law spatial spectrum of the cor- relation function was formulated, including an aspect ratio for two mutually perpendicular transverse (to the geomagnetic field) directions as well as a longitudinal to transverse one. The model of the electron density fluctuations is given by:

$$
\begin{gathered}
\Psi_{N}(\mathbf{k}, \mathbf{R})=\frac{\alpha \beta \Gamma(p / 2) \sigma_{N}^{2}(R)}{\kappa_{0}^{3} \pi^{3 / 2} \Gamma((p-3) / 2)} \\
\left(1+\frac{\kappa_{x}^{2}+\beta^{2} \kappa_{y}^{2}+\alpha^{2} \kappa_{z}^{2}}{\kappa_{0}^{2}}\right)^{-\frac{p}{2}}, \kappa_{0}=\frac{2 \pi}{L}
\end{gathered}
$$

$\alpha$ is the along-magnetic field and $\beta$ the across- 


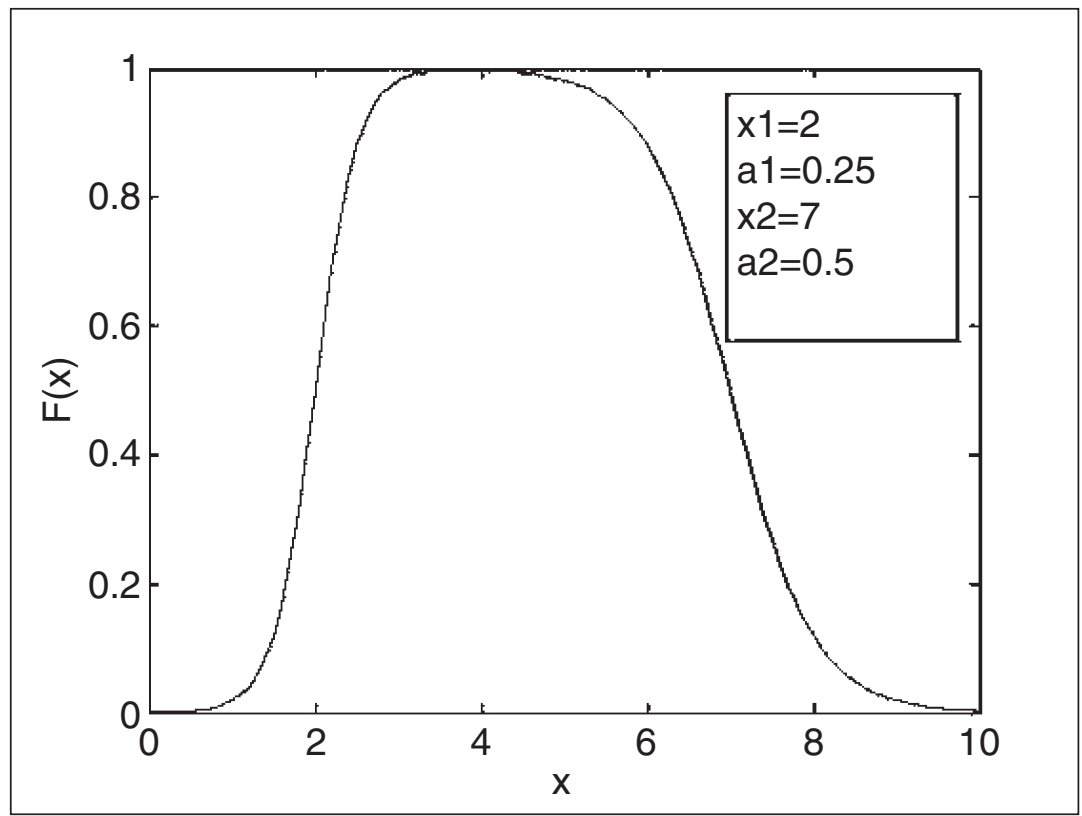

Fig. 10. Plasma bubble/polar patch model.

magnetic field aspect ratio. $k_{0}=\frac{2 \pi}{L}$ where $\mathrm{L}$ is the smallest outer scale of the fluctuations. The variances of the fractional electron density fluctuations along the ray paths are given by;

$\sigma_{f r}^{2}(r, t)=\sigma_{0 f r}^{2}(r, t) \cdot\left[1+B \cdot \Phi\left(r, r_{1}(t), v_{1}, r_{2}(t), v_{2}\right)\right]$

Details of the propagation model, calculation of the two-point correlation and cross correlation functions of the phase and log-amplitude of the field, estimation of the statistical characteristics of the received field and resultant simulated time series of received amplitude and phase can be found in (Gherm et al., 2005; Maurits et al., 2008).

The parameters of the spectrum of the electron density fluctuations, as well as the meso-scale local polar structures (e.g. bubbles or patches) are chosen empirically. The NeQuick model [http://www.itu.int/ITU-R/study-groups/softwa- re/rsg3-p531-electron-density.zip] was used to describe the low latitude/equatorial ionosphere. (Gherm et al., 2007; Strangeways et al., 2007) describe using the meso-scale model to predict scintillation effects for bubbles and the good agreement obtained with experimental data taken at Douala, Cameron (Maurits et al., 2008; Zernov et al., 2008; 2009) describe the application to modelling propagation through polar patches.

The University of Alaska, Fairbanks Eulerian Parallel Polar Ionosphere Model was used to represent the large-scale background polar ionosphere.

The resultant propagation simulator enabled realistic predictions of the scintillation effects for high-latitude transionospheric propagation at $L$ band (e.g. GPS signals) in the presence of polar patches for a number of different propagation scenarios for $L$-band transionospheric signals. For some more restricted conditions, the propagation model can also produce results for lower frequencies, such as $400 \mathrm{MHz}$, where the regime of strong scintillation arises. 


\section{REFERENCES}

Altuntas, E. (2007): Forecasting of the EM Waves in Ionised Media Related to Aerospace Applications, MS Thesis, Aerospace Eng., Middle East Technical Univ., (Ankara, Turkey, Sep. 2007).

Belehaki, A., LJ.R. CANDER, B. Zolesi, J. BReMER, C. JuRen, I. Stanislawska, D. Dialetis and M. Hatzopoulos (2007): Ionospheric specification and forecasting based on observations from European ionosondes participating in DIAS project, Acta Geophysica, 55 (3), 398-409.

Bremer, J., Lu.R. Cander, J. Mielich and R. Stamper (2006): Derivation and test of ionospheric activity indices from real-time ionosonde observations in the European region, Journal of Atmospheric and Solar-Terrestrial Physics, 68 (18), 2075-2090.

CANDER, LJ.R and S.J. MiHAJLOVIC (2005): Ionospheric spatial and temporal variations during the 29-31 October 2003 storm, Journal of Atmospheric and Solar-Terrestrial Physics, 67 (12), 1118-1128.

CANDER, LJ.R. and L. CiRAOLo (2008): Total Electron Content over Europe at Solar Minimum: Storm Case, 1st GNSS Vulnerabilities and Solutions Conference, (Baška, Croatia, 7-9 September).

CANDER, LJ.R. (2009): Ionospheric ground-based measurement networks, in Proceedings of the International Heliophysical Year, Earth, Moon and Planets, 104, 37-40, doi:10.1007/s11038-008-9245-z.

Cop, R., S.J. MihaJlovic and LJ.R CANDeR (2008): Magnetic Storms and their Influence on Navigation, Pomorstvo, Journal of Maritime Studies, 22 (1), 89-99.

Fotiadis, D.N., S.S. KouRIS, V. RomANo and B. ZolesI (2004): Climatology of ionospheric $F$-region disturbances, Annals of Geophysics, 47 (5), 1311-1323.

GHERM, V.E., N.N. Zernov and H.J. StrangewAYs (2005): Propagation model for transionospheric fluctuating paths of propagation in a wideband ionospheric fluctuating reflection channel: Physically based software simulator of the transionospheric channel, Radio Science, 40 (1), RS1003, doi:10.1029/2004RS003097.

GHerm, V.E., N.N. Zernov and H.J. STRANGEWAYs (2007): Modelling of the effect of strong scintillation on GPS Signals due to plasma bubbles in the low-latitude ionosphere, presented at COST 296/IRI meeting (Prague, Czech Republic, 10-14 July, 2007).

Kouris, S.S., LJ. R. CANDER and K.V. Polimeris (2005): On the variability of the slab thickness, ESA/ESTEC, 2nd European Space Weather Week, (14-18 November 2005, Noordwjk, The Netherlands), ESA-ESWW2.

Kouris, S.S., K.V. Polimeris and LJ. R. CANDER (2006): Specifications of TEC variability, Adv. Space Res., 37, 983-1004, doi:10.1016/j.asr.2005.01.102.

Kouris, S.S., K.V. POlimeris, LJ. R. CANDER and L. CiraOLO (2008): Solar and latitude dependence of TEC and slab thickness, Journal Atmos. Solar-Terr. Phys., doi:10.1016/j.jastp.2008.03.009.

Kouris, S.S., K.V. Polimeris, L. CiRAOLO and D.N. Fotiadis (2009): Seasonal dependence of TEC and slab thickness, Adv. Space Res., doi:10.1016/j.asr.2008.10.036.

Kutiev, I., P. Marinov and S. Watanabe (2006): Model of topside ionosphere scale height based on topside sounder data, Adv. Space Res., 37 (5), 943-950, doi:10.1016/j.asr.2006.06.013.
KutIEv, I. and P. MARINOV (2007): Topside sounder model of scale height and transition height characteristics of the ionosphere, Adv. Space Res., 39, 759-766.

Kutiev, I., P. Marinov, A. Belehaki, B. Reinisch and N. JAKOWSKI (2009): Reconstruction of Topside Density profile by using the topside sounder model profiler and digisonde data, Adv. Space Res., 43 (11), 1683-1687.

Jansen, F., P. Beck and Lu.R. CANDER (2006): Space weather impacts on aviation and radio communications, in Proceedings of the International Heliophysical Year, First European General Assembly, (10-13 January 2006, Paris, France), pp. 9.

Marinov, P., I. Kutiev and S. Watanabe (2004): Empirical model of $\mathrm{O}^{+}-\mathrm{H}^{+}$transition height based on topside sounder data, Adv. Space Res., 34, 2015-2022.

Maurits, S.A., V.E. GHerm, N.N. Zernov and H.J. STRANGEWAYS (2008): Modeling of scintillation effects on high-latitude transionospheric paths using ionospheric model (UAF EPPIM) for background electron density specifications, Radio Science, 43, RS4001, doi:10.1029/2006RS003539.

Middleton, H.R., S.E. Pryse, L. Kersley, G.S. Bust, E.J. Fremouw, J.A. Secan and W.F. Denig (2005): Evidence for the tongue of ionisation under northward IMF conditions, J. Geophys. Res., 110 (A7), A07301 10.1029/2004JA010800.

Middleton, H.R., S.E. Pryse, A.G. Wood and R.L. BaltHAZOR (2008): The role of the tongue-of-ionisation in the formation of the poleward wall of the main trough in the European post-midnight sector, J. Geophys. Res., 113 (A2), A02306, doi:10.1029/2007JA012631.

Muhtarov, P., I. Kutiev and Lu. R. CANDER (2002): Geomagnetically correlated autoregression model for short-term prediction of ionospheric parameters, Inverse Problems, 18, 49-65.

Perrone, L. and G. De Franceschi (1999). A correlation study between time-weighted magnetic indices and the high latitude ionosphere, Physics and Chemistry of the Earth, 24 (4), 389-392.

Perrone, L., M. Pietrella and B. Zolesi (2007): A Prediction model of $f o F 2$ over periods of severe geomagnetic activity, Adv. Space Res., 39, 674-680.

Pietrella, M., L. Perrone, G. Fontana, V. Romano, A. Malagnini, G. Tutone, B. Zolesi, Lu.R. Cander, A. Belehaki, I. Tsagouri, S.S. Kouris, F. Vallianatos, J. MAKRIS and M. ANGLING (2009): Oblique-incidence ionospheric soundings over Central Europe and their application for testing now casting and long term prediction models, Adv.Space. Res., 43 (11), 1611-1620.

Pryse, S.E, L. Kersley, D. Malan and G.J. Bishop (2006a): Parameterization of the main ionospheric trough in the European sector, Radio Science, 41, RS5S14, doi:10.1029/2005RS003364.

Pryse, S.E, A.G. Wood, H.R. Middleton, I.W. McCrea and M. LESTER (2006b): Reconfiguration of polar-cap plasma in the magnetic midnight sector, Ann. Geophysicae, 24 (8), 2201-2208, (available on line at www.anngeophys.net/24/2201/2006/).

PRYSE, S.E, H.R. MidDLETON and A.G. Wood (2007): Llif yr atmosffer drydanol dros begwn y gogledd: arsylwadau tomograffi radio a SuperDARN, Gwerddon, 1 (2), 3856, (ISSN 1741-4261), (available on line at www.gwerddon.org/2_llif_yr_atmosffer_drydanol_- 73.aspx). 
PrySE, S.E., E.L. WhitTick, A.D. Aylward, H.R. MidDleton, D.S. Brown, M. LeSTER and J.A. SeCAN (2009): Modelling the tongue-of-ionisation using CTIP with SuperDARN electric potential input: verification by radiotomography, Ann. Geophysicae, 27, 1139-1152, (available on line at www.ann-geophys.net).

Rawer, K., S.S. Kouris and D.N. Fotiadis (2003): Variability of $F 2$ parameters depending on modip, $A d v$. Space Res., 31 (3), 537-541.

SEnALP, E.T. (2007): Cascade Modeling of Nonlinear Systems, Ph-D Thesis, (Electrical and Electronics Eng., Middle East Technical Univ., Ankara, Turkey).

Senalp, E.T., E. Tulunay and Y. Tulunay (2008): Total Electron Content (TEC) Forecasting by Cascade modeling: a possible Alternative to the IRI-2001, Radio Science, 43, RS4016, doi:10.1029/2007RS003719.

Stankov, S.M., P. Marinov and I. KuTIEV (2007): Comparison of NeQuick, PIM, and TSM model results for the plasma scale and transition heights, Adv. Space Res., 39, 767-773, doi:10.1016/j.asr.2006.10.023.

Strangeways, H.J., V.E. GHERM and N.N. ZERNOV (2007): Modeling and mitigation of the effect of scintillations on GPS, paper at 49th International Symposium ELMAR-2007, (12-14 September 2007, Zadar, Croatia. Conference Proc.) pp. 69-73, available online in IEEE Xplore, doi:10.1109/ELMAR.2007.4418802.

Triskova, L., I. Galkin, V. TRUhliK and B.W. Reinisch (2007): Application of seamless vertical profiles for use in the topside electron density modeling, $A d v$. Space Res., 39, 774-778.

Tulunay, E., Y. Tulunay, E.T. Senalp and Lu.R. CAnder (2004): Forecasting GPS TEC Using the Neural Network Technique «A Further Demonstration», Bulgarian Geophysical Journal, 30 (1-4), 53-61.

Tulunay, E., E.T. Senalp, S.M. Radicella and Y. Tulunay (2006): Forecasting Total Electron Content Maps by Neural Network Technique, Radio Science, 41 (4), RS4016.

Wheadon, N.S., R. LaRsen, A. Belehadi, LJ. R. CANDER, B. Zolesi, J. Bremer, C. Juren, I. Stanislawska, D. Dialetis and M. Hatzopouloss (2006): Exploitation of the European Digital Upper Atmospheric Server (DIAS) for Radio Systems Applications, in Proceedings of the IET Conference on Ionospheric Radio Systems and Techniques, (18-21 July 2006, London, UK).

WhitTick, E.L., S.E. Pryse, H.R. MidDLETon, A.R. LotingA and A.D. AYLWARD (2009): The CTIP Model with SuperDARN electric potential patterns as input: first comparison of modelled ion densities with radio tomography observations, Earth, Moon and Planets, 104 (1), 45-49, doi:0.1007/s11038-008-9264-9, (available on line at www.springerlink.com/content/53w6472172p73808/).

Wood, A.G., S.E. Pryse, H.R. Middleton and V.S.C. Howells (2008): Multi-instrument observations of nightside plasma patches under conditions of IMF Bz positive, Ann. Geophysicae, 26, 2203-2216, (available on line at http://www.ann-geophys.net/26/2203/2008/).

WrenN, G.L. (1987): Time-Weighted accumulations ap(t) and $\mathrm{Kp}(\mathrm{t})$, J. Geophys. Res., 92 (10), 125-10, 129.

WU, J. and P.J. WILKINSON (1995): Time-weighted indices as predictors of ionospheric behaviour, J. Atmos. Terr. Phys, 57, 1763-1770.

YAPICI, T. (2007): Influences of interplanetary magnetic field on the variability of the aerospace media, MS Thesis, Aerospace Eng., (Middle East Technical Univ., Ankara, Turkey, Sep. 2007).

Zernov, N.N., V.E. GHERm and H.J. StRANGeways (2008): The scintillation propagation model for the effects of scintillation on transionospheric paths traversing midscale ionospheric inhomogeneities, COST296 Workshop «Ionospheric scintillation: Scientific aspects, Space weather, Application and services», (Nottingham, UK, 20-22 February, 2008).

Zernov, N.N., V.E. GheRm and H.J. Strangeways (2009): On the effects of scintillation of low latitude bubbles on transionospheric paths of propagation, Radio Science, 44, RS0A14, doi:10.1029/2008RS004074.

Zolesi, B., G. Fontana, L. Perrone, M. Pietrella, V. Romano, G. Tutone, A. Belehaki, I. Tsagouri, S.S. Kouris, F. Vallianatos, J.P. Makris and M.J. ANGLING (2008): A new campaign for oblique-incidence ionospheric sounding over Europe and its data application, J. Atmos. Sol. Terr. Phys., 70, 854-865.

Zolesi, B., and LJ.R. CANDER (2008): From COST 238 to COST 296: Four European COST Actions on Ionospheric Physics and Radio Propagation, in AIP Conference Proceedings, 974, 39-46.

Zolesi, B., LJ.R. CANDER, A. Belehaki and I. Tsagouri (2008): Effective sunspot number: A tool for ionospheric mapping and modelling, XXIX General Assembly of URSI, (Chicago, USA, 07-16 August 2008). 